\author{
"Your Brain Becomes a Rainbow": Perceptions and Traits of Fourth Graders \\ in a School-Based Mindfulness Intervention \\ Julia Keller \\ University of New Mexico
}

Eric Ruthruff

University of New Mexico

Patrick Keller

University of New Mexico

\author{
Robert Hoy \\ University of New Mexico \\ Nicholas Gaspelin \\ University of California, Davis \\ Katherine Bertolini \\ South Dakota State University
}

Author Note

This study was supported by a grant from the Mind and Life Institute. Correspondence concerning the article should be directed to Julia Keller's email: jkelle01@unm.edu 


\begin{abstract}
While mindfulness (MF), or the self-regulation of attention, has been found beneficial in reducing teacher stress and burnout and in increasing students' cognitive and emotional regulatory skills, no study has explored students' attitudes toward meditation practices in depth. This mixed-methods study reports results from a randomized, controlled trial of a ten-week MF intervention in a public school setting with 28 fourth-grade students from lower income and ethnic minority backgrounds. Over the course of the intervention, students were asked to respond to writing and drawing prompts about their feelings and attitudes toward MF. At the end of the intervention, the experimental teacher rated students on how often they had practiced MF breathing during class. Qualitative analysis of journal entries yielded personality traits of students who were receptive or resistant to MF training. Practical strategies for identifying and remediating resistant students and for implementing mindfulness interventions in a school setting are discussed.
\end{abstract}




\section{"Your Brain Becomes a Rainbow": Perceptions and Traits of Fourth Graders in a School-Based Mindfulness Intervention}

One of the most significant challenges facing interventionists who want to implement mindfulness (MF) training in a school-based setting is the subset of children who dislike and resist the practice. "I hate mindful class. I hate mindful class," wrote one fourth grader in his journal. He also said that MF was boring on many occasions during MF interventions. Other students, however, are receptive to MF. This fourth grade boy wrote, "To me mindfulness breathing means it gives your stress to happiness. When your stress comes, your brain will become a storm, but when you do mindful breathing your brain becomes a rainbow." What are the perceptions and traits of children who are receptive to MF treatment and children who are not? How can teachers, parents, counselors, and administrators respond intelligently and compassionately to resistant children? The present research addressed these issues.

The self-regulation of attention and emotion is a critical skill for students to master because it allows them to learn efficiently and work well with others. Emotional awareness, arguably the first step towards regulation, is associated with decreases in self-reported somatic complaints, social anxiety, depression, and a tendency to worry or ruminate (Rieffe, Oosterveld, Miers, Terwogt, \& Ly, 2008). MF is one well-established technique for developing the ability to self-regulate attention and emotion. Specifically, MF is the cognitive ability to pay attention to the present moment without judgment or attachment to a desired outcome (Kabat-Zinn, 1994). Studies have consistently demonstrated benefits of MF training, including reduced pain and stress (Majumdar, Grossman, DietzWaschkowski, \& Walach, 2002), improvements in cognitive functioning (Chiesa, Calati, \& Serretti, 2011; Tang \& Posner, 2009), increases in positive emotion (Davidson et al., 2003), and the ability to inhibit emotionally charged but irrelevant information (Ortner, Kilner \& Zelazo, 2007). Although school-aged children would seem to have the most to gain from learning MF, the vast majority of MF studies have focused on adults.

Schools are an excellent place to teach MF because substantial numbers of children can be taught how to use MF to improve their learning and social skills and, to integrate MF into their daily routines. This approach has potential to improve children's academic prospects. A study by Napoli, Krech, and Holley (2005) investigated the impact of MF training on the attentional abilities of 254 first, second, and third grade students. Students were randomly assigned to the experimental group who received MF training $(N=114)$ or to the control group who participated in reading or other quiet activities $(N=114)$. Before and after the MF training, each child was assessed 
on three established measures: The ADD-H Comprehensive Teacher Rating Scale (Ullmann, Sleator \& Sprague, 1997), the Test of Everyday Attention for Children (TEA-Ch; Manly, Nimmo-Smith, Watson, Anderson, Turner, \& Robertson, 2001), and the Test Anxiety Scale (Sarason, 1978). Results showed substantial differences ( $d=.49)$ between those who did and did not receive MF training. Paired $t$-tests on the difference scores between pre-tests and post-tests showed statistically significant MF benefits on the TEA-Ch selective attention subscale $\left(\mathrm{t}_{\mathrm{diff}}=7.94, p<\right.$ $.001)$, the ACTeRS Social Skills Subscale ( $\left.\mathrm{t}_{\text {diff }}=-7.19, p=.001\right)$, and the Test Anxiety Scale $\left(\mathrm{t}_{\text {diff }}=-1.34, p=.007\right)$. While these are some of the proven benefits of MF training in schools, other researchers speculate that MF training could also prepare students for creative activities like brainstorming and journal writing (Fisher, 2006). MF might also help them see problems in a new light and from multiple perspectives (Napoli, Krech, and Holley, 2005).

MF training also improves emotion regulation by decreasing maladaptive strategies (e.g., rumination) while increasing tolerance for negative mood states (Corcoran, Farb, Anderson, \& Segal, 2009). Emotion regulation improves the likelihood of academic success by enabling students to develop stress-management tools and the selfdiscipline necessary for academic goal attainment (Waters, Barsky, Ridd, \& Allen, 2015). Waters et al. (2015) examined 15 peer-reviewed studies on the effect of school meditation interventions on well-being, social competence, and academic achievement. Two studies $(n=231)$ found that meditation significantly increased standardized test scores. Six of the 15 studies $(n=762)$ examined the impact of meditation on emotion regulation. In three of these studies, meditation significantly improved emotional regulation and in a fourth study (Broderick \& Metz, 2009), MF practice significantly reduced negative affect.

Evidence from qualitative research also suggests that meditation improves emotion regulation. While qualitative research is often considered to be less objective, understanding participants' subjective experience is essential for a comprehensive understanding of the human mind and experience (Varela, 1996). Rosaen and Benn (2006) interviewed 10 seventh-graders who had been practicing Transcendental Meditation for a year. The students reported that they had more self-control and were more aware of their emotions and more flexible in their emotional responses. Campion and Rocco (2009) interviewed 54 elementary students, 19 teachers, and seven parents about a Christian meditation program taught to over 10,000 students in an Australian Catholic diocese. Eighty percent of the students interviewed reported that meditation had a calming and relaxing effect on them and $36 \%$ stated that it had improved their anger management skills. 
While Campion and Rocco (2009) reported a generally positive attitude towards meditation in the student participants, thirty-two percent of the teachers reported negativity towards meditation from some students, $32 \%$ recounted resistance from students who had difficulty sitting still, and two of the teachers mentioned that some students were bored. While other studies have also briefly mentioned students' negative attitudes toward meditation (Semple, Reid, \& Miller, 2005), no study has explored students' attitudes toward meditation practices in depth.

One promising method that is well-regarded but has not yet been used to study student attitudes of MF is journal writing, a type of reflective practice. Journal writing is one method for processing the raw material of experience and making sense of confusing and conflicting thoughts and emotions (Boud, 2011). It is also a form of self-report, or a participant's representation of their mental and emotional perceptions during a therapeutic experience. Self-reports by children are not usually regarded as fully objective measurements, "but only the child is capable of reporting on his or her own internal thoughts and emotions from a subjective perspective, especially with regard to the treatment process and outcomes" (Hamama \& Romen, 2009, p. 92). Denzin and Lincoln (1994) also stated that understanding what was occurring in the minds of students was essential for critical pedagogical research.

\section{The Present Study}

Our study goals were to explore whether MF can be effectively integrated into the curriculum and administered in school settings by classroom teachers, and to investigate how children's conceptualization of MF and its relevance to their lives changes over time. Data collected from teacher surveys, children's drawings, children's journal entries, and results from correlational analyses helped us address these goals.

The present study was a mixed-methods, longitudinal study in which data were collected on the developmental growth of attention, working memory, and emotional regulation in low-income, minority children (89\% Hispanic; 11\% Black) receiving a MF intervention over a ten-week period (see Figure 1 for a simplified timeline of study events). Race, ethnicity, and socioeconomic status are associated with chronic stress caused by inadequate nutrition, poor living conditions, high unemployment, and high levels of crime and violence. Children who grow up in poverty have greater difficulty regulating their emotions and behavior and are at an increased risk for developing social and emotional difficulties (Evans \& English, 2002). To date, only a few studies have explored the effects of MF training on urban, minority populations (Roth \& Robbins, 2004).

\section{Method}

\section{Participants}


28 fourth-grade students (64\% female) from low-income families in a large urban district in the Southwest participated in this study. Informed assent was obtained from all participants and consent forms were signed by their parents.

\section{Measures}

After completion of pre-tests (see Table 1), participants were matched on attention and working memory (WM) scores and randomly assigned to a mindfulness or control condition. All participants completed 27 sessions during their 90-minute reading/writing class. The experimental group $(n=15)$ received instruction in MF practices while control students $(n=13)$ sat quietly for 10 minutes/day at the beginning of their literacy class. Before the intervention started, and before random assignment to condition, the teacher rated her students from 1-4 on average level of attention during instruction, with 4 representing excellent attention. After treatment, the experimental teacher rated how often students had practiced MF breathing during class from 1 to 4 (1=Very little or Never, 2=Sometimes, $3=$ Most of the time, 4=Always or Almost Always). The first author also independently rated students on frequency of practice while facilitating the class. For the purposes of this report, students who were rated by both as a "3" or a "4" are referred to as the Practicing More (practiced more frequently; $n=7$ ) group; students who were rated by the teacher as a "1" or a "2," but rated as a "3" by the first author are referred to as the Practicing More with Instructor (MWI; $n=3$ ) group; students who were rated by both the teacher and the first author as a "1" or a "2" are referred to as the Practicing Less (practiced very little or only sometimes; $n=5$ ) group.

Over the course of the intervention, students were asked to respond to writing prompts in their journals in order for the teacher and the first author to determine their progress in the understanding and application of MF to academic and personal situations. Some of the prompts were generated by the first author and some were generated by the fourth-grade teacher (see Appendix for a list of the writing prompts). The experimental teacher also completed open-ended questions about MF and reading lessons in an online daily survey, as well as a closed-ended question on the daily length of her MF practice.

\section{MF Practices}

The components of the intervention were grounded in the work of Saltzman (2004) and on the first author's experience of 17 years as an elementary teacher, 12 years practicing MF, and 6 years of instruction and research in the MF field. The first author facilitated 7 of 27 instructional sessions, also providing lesson plans and strategies to 
the classroom teacher on teaching and integrating MF into her literacy class. The fourth-grade teacher, completed a mindfulness-based stress reduction (MBSR) course and taught the remaining 20 lessons.

A variety of MF practices were introduced during the intervention. Breathing with the bell was the most common practice. The teacher taught students to sit up and take 5-10 breaths after she rang a bell. She used the bell as a way to transition between activities. HeartMath (http://www.heartmath.com): Interactive hardware/software monitored and displayed heart rate variability (HRV) patterns as students practiced breathing mindfully. Listening to guided meditations for children in class: We gave experimental students their own copy of Amy Saltzman's (2007) Still, Quiet Place CD and instructed them to listen to a guided meditation once/day, and record their practice on a page they would return to the teacher with their parent's initials. They also listened to this CD in class. $M F$ listening: Listening with the mind and heart to other students and the teacher when they were speaking. MF eating: This practice occurred 5 times with candy or chips that children enjoyed tasting mindfully.

\section{Qualitative Data Analysis}

In a social constructionist framework (Denzin \& Lincoln, 1994), it is important to understand how students socially construct their consciousness. Teacher-researchers focus on uncovering student motives, values, and emotions. Grounded in this framework, the first author used an open-coding process to analyze journal entries. With the help of a qualitative software package (Dedoose Version 6.1.9, 2015), The first author carefully read the journals, highlighting excerpts in the text that seemed relevant (Merriam, 2009), and creating codes that reflected her first impression of the excerpt's content. The first author often coded excerpts with more than one emerging theme for understanding the students' experience of MF and their personal characteristics. Then, after creating an initial set of codes, she re-read the journals, going through an iterative process where minor codes were eliminated, re-sorting and combining the remaining codes into larger and larger categories, distilling recurring ideas and meaningful patterns from the data, and finally synthesizing the codes/patterns into conceptually unique themes (Averill, 2013). General themes included the following: Benefits of MF practice, Liked Activities, MF Definitions or Understanding of MF, MF practices, Negative Feelings toward MF, and Negative Feelings Without Mentioning MF. Additionally, member checking, or respondent validation, a technique wherein a researcher increases internal validity by soliciting feedback from key participants in a study, was obtained from the experimental teacher regarding the study findings.

\section{Quantitative Results}


Results were analyzed to determine whether MF improved self-regulation of attention and emotion, on average. Sets of difference scores on the surveys were calculated by subtracting Time 1 (T1) from Time 5 (T5) and then $t$-tests were conducted on each of the measures in Table 1, including group (experimental vs. control) as a between-subjects factor and high vs. low practicing as another between-subjects factor. All comparisons were nonsignificant (see Table 2 for group means and Table 3 for means of experimental groups who practiced MF more or less frequently in class as rated by the teacher).

Correlational analyses on the seven post-tests and the teacher ratings revealed that the Child and Adolescent Mindfulness Measure (CAMM) and the Emotion Awareness Questionnaire (EAQ; $r=.69$ ), the CAMM and the Spence Children's Anxiety Scale (Spence; $r=.54$ ), and the EAQ and Spence $(r=.61$ ), were highly correlated $(p<.01)$. Additionally, the teacher's ratings of student MF practice were positively correlated with the post Reading Attitude Inventory (RAI; $r=.728 ; p<.01$ ). There was a non-significant trend towards a positive relationship between teacher ratings and post CAMM $(r=.303 ; p>.10))$. Thus, diligent MF practice during reading lessons was strongly correlated with an increase in positive attitudes towards reading and it might have also led to an increase in mindfulness (though that trend did not quite reach significance). The teacher's ratings were negatively correlated with the Simon effect $(r=-.564 ; p<.01))$, which is thought to reflect attentional control. Specifically, it is the response time slowing that occurs when the required response is incompatible with an irrelevant stimulus dimension (e.g., the fish is pointing left but is on the right side of the screen). This finding is consistent with the hypothesis that students who practice MF on a regular basis developed greater attentional skills. All other correlations were non-significant.

\section{Qualitative Results}

Early on during the intervention, it became apparent that students were responding to the MF intervention differently. Some were receptive to the training, while others were resistant. Since one of our main study goals was to study which MF practices are most effective for which types of children, during the open coding process the first author looked for specific personality traits of children who were receptive or resistant to MF training in order to better understand possible reasons for their differing attitudes. During the course of the intervention, the teacher and the first author asked students to answer specific writing prompts about their feelings and thoughts regarding MF (see Appendix). Students' answers to these prompts, along with their drawings, provided the main source for the qualitative analysis. To avoid single-source bias and increase internal validity, triangulation (comparing and cross- 
checking data collected at different times or places; Merriam, 2009) of multiple sources of data (children's drawings, journal excerpts, cognitive and self-report measures, the teacher's online surveys, and teacher observations) is provided when relevant. The participant's names have been changed to maintain confidentiality. The original spelling of the fourth-graders has been preserved (with bracketed corrections) when excerpts are cited.

Children's drawings. Children's drawings are a window into their inner lives, revealing their emotions, perceptions, and conceptions of the world (Hamama \& Romen, 2009). Drawings reflect a child's unconscious perceptions and feelings (Faroki \& Hashemi, 2011), while their writing reflects their explicit, conscious thoughts and feelings. Hopperstad (2010) discussed the interpretation of visual features in drawings in order to derive ideational, interpersonal, and textual meaning from them. Ideational meaning is what an image communicates about a specific phenomenon. In Figure 2, the students were asked at the close of the intervention to "draw a picture of yourself practicing mindfulness." Thus, these drawings represent the children's conceptions of MF practice. They are also analytical in nature, in that students included elements important to MF, such as a visual representation of the breath. The interpersonal meaning of an image can be found in the gaze of the illustrated person-is it looking directly or indirectly at its potential viewers? In the majority of the MF drawings, the students (7/13) have their eyes closed or are in profile, relating to us in a more open and relaxed manner, also communicating the importance of closed eyes and/or relaxation. The eyes of the remaining six students are open, demanding a higher level of interaction with the viewer. Textual meaning can be derived from the use of graphic lines for framing separate components of the image. For example, Sophia used lines to separate different words that she associated with MF practice - "feelings mad sad happy, calming down, breath, participate."

Emotional attitudes toward the phenomenon in question can also be seen in drawings (Hamama \& Romen, 2009). In $6 / 13$ of the participants' drawings, the figures are smiling, indicating feelings of happiness during MF practice. Ethan and Aman's straight or slightly down-turned mouths may indicate anxiety or uncertainty, and Emilio's bared-teeth expression may indicate stress (Sturner \& Rothbaum, 1980). Fluent lines in a drawing demonstrate confidence, while one with many erasures — as in Ethan's drawing--may show anxiety (Hamama \& Romen, 2009). The student's drawings demonstrated the important elements of MF practice-a round, open mouth (4/13 students), closed eyes (6/13), listening to a CD or music (2/13), sitting cross-legged (5/13), lying down (1/13), and focusing on the breath (5/13). In seeking to understand more about why some children were more or less receptive to the MF treatment, we can learn a lot about their emotional attitudes and perceptions from their 
drawings. The drawings of the students in the Practicing More group and the More with Instructor group — with the exception of Ethan and Aman, whose drawings indicated some anxiety—all have smiling, happy faces. The students in the Practicing Less group — with the interesting exception of Sebastian — are not smiling.

Experimental group themes in Journal Entries. The most saturated themes within each of the subgroups are discussed in detail below. Figures 5-7 show the themes that are important in understanding each of the sub-groups: Practicing More, More with Instructor, and Practicing Less.

Practicing More group themes. Next, we analyzed the themes for those who practiced MF more diligently during the intervention. Importance of a theme to each subgroup can be seen in the percentage of excerpts that each group contributed to the theme. For example, the Practicing More group $(n=7)$ represented $47 \%$ of the experimental group $(n=15)$ so, in Figure 4, any theme where the Practicing More group contributed over $47 \%$ of the excerpts indicated the theme's importance to some or all of the members of that group. This means that, while answering the journal prompts, students did more than just provide a simple answer to the question; they wrote more than students in other groups on this theme: MF as suppressing bad thoughts (8/13 excerpts), MF as beneficial (101/182), Helps with negative emotions (18/34), MF and positive feelings (63/104), and MF as breathing (32/55). Abigail's excerpt showed that MF breathing is an important part of her life. "If you breath [breathe] you get to feel better if your [you're] mad, sad, or happy. Well if your [you're] happy then you can breath [breathe] every single minute or second or every day."

Three themes in Table 5 demonstrate the Practicing More group's positive attitudes toward school: Like being good (8/8 excerpts), Like schoolwork or learning (12/13 excerpts), and Like teacher (4/5 excerpts). In four excerpts, Jacinta revealed that she liked being perceived as "good." "I would call myself good because people call me, respectful, responsible, and safe. My teatcher [teacher] always tells me that I listen and I'm a good student." In 12 excerpts, the Practicing More group stated that they liked reading, listening, and learning. Kevin said that he liked reading because he got to learn and it made him smart. Violeta expressed that she liked learning about "all kinds of stuff" like math, science, reading, and writing. And in four excerpts, the Practicing More group wrote that they liked their teachers.

Positive self-esteem. The Practicing More group also thought of themselves as good students (8 excerpts) and as smart (6 excerpts). Abigail said she would call herself smart and her teacher said she was smart. Their teacher's good opinion of them was important to this group and it was also important for them to do well in school. 
Jacinta wrote, "I am a leader because, I am a good student. I would make good grades... Just to let you know I made (honor roll)." Ethan was the only member of this group who was not as confident of himself. "I guess I am good. I guess I am smart. I guess I am a leader." His image of himself practicing MF also looked worried and was filled with erasure lines. Santino, in the Practicing Less group, wrote that Ethan was one of his friends with whom he played sports and video games. Ethan, a quiet and shy boy, may have found it difficult to be a good student when his friends were acting out in class. But overall, the Practicing More students seemed to have a more positive selfimage.

Like MF and MF as fun. In addition to positive attitudes about school, the Practicing More group also had more positive feelings about MF. In response to the prompt, "Do you prefer to be mindful or mindless?" $5 / 6$ of the Practicing More students said they preferred being mindful because it made them happy and relaxed. Ethan was the only exception. "I prefer [prefer] mindless. It makes me calm, happy and relaxed becans [because] for baseball you have to be mindless and I love baseball, baseball is my favorite sport." The level of enthusiasm for MF as fun was highest in the Practicing More group. "Mindful is just haveing (having) fun!" wrote Ashley. "I do like it because I [it] is calming, fun, and it tast [tasted] good some of the time. I love it" (Violeta).

Lovingkindness, compassion, being nice. The practice of sending well wishes to others (lovingkindness meditation) is an important part of MF training that has been linked to increases in social connectedness and decreases in social isolation (Hutcherson, Seppala, \& Gross, 2008). However, it is difficult to teach lovingkindness practices to a group of children who do not feel safe with each other, so we only taught one lesson and gave one writing prompt on this topic. Yet the students, especially the Practicing More group, wrote 26 excerpts demonstrating an awareness/desire to be kind, compassionate, being good (to others) or nice. Violeta wrote about loving other people five times and her definition of MF was "that your mind is calm with goodness." In an individual prompt, the first author asked her to draw the picture in her head that she saw when she practiced. She drew a figure with a heart-shaped face and stick arms spread open wide in an embrace of the world. The significance of the heart can also be found in Violeta's excerpts in the theme MF as expressing or "feeling" or "listening to the heart." When she wrote about hugging her mom, Violeta said, " I nodest [notice] whomth [warmth] in my hart [heart]." Noticing and expressing emotion was an essential element of MF for this girl, who often got into conflicts with other children. At the end of the intervention, Violeta wrote that MF was about deep breathing and expressing feelings whether when mad or when eating. 
MF as practice or goal or doing it "right". In addition to being conscientious students, the Practicing More group was also conscientious about MF practice. They were the only ones who used the word "practice" in relation to MF breathing. "I am going to practice because I think I need to get good at it" (Ashley). They also expressed the desire to improve at it. "When you have a class that dose (does) mindful breathing you have to do it every day and when you practice it you get better and better" (Abigail). The bell, referred to as "the breathing bell" 19 times by the teacher in her daily survey, was the students' most frequent opportunity for improving their practice, but only the students in the Practicing More group talked about the bell. Ashley mentioned it five times: "I can ring the bell to make me feel happy."

The Practicing More students were also the most attentive students in class. Rated by their teacher on attentiveness during instruction (1-4, with 4 being the most attentive) before the intervention started (the correlation between the teacher's attention ratings and MF practice ratings was .737, $p=.01$ ), all of the Practicing More students were given a "3" or a "4." While all of the students wrote about MF and attention, concentration or focus, 16/30 excerpts in this category came from the Practicing More group. "Mindfulness is to concentrate on what's around and inside you," wrote Jacinta, who used the word "concentrate" four times, and also said that MF was letting go of other thoughts and that it might help her do better on tests. The Practicing More group also recognized that it was easier to concentrate in a quiet room, and they were more likely to answer the question, "When is a good time to practice?" by saying they would practice at home as well as at school. Ashley answered this prompt with the excerpt: "Befor [before] work. Befor school. Befor you go to bed. Befor you go outside. Befor anything is good."

In summary, students in the Practicing More group reported more benefits from MF practice, they liked being good, and they liked their teacher and learning. They saw themselves as "good" and "smart." They liked MF and saw it as "fun." They had a desire to be kind or nice. Their excerpts demonstrated a more advanced understanding of MF meditation - the perception of MF as something that can be improved with daily practice given the right conditions (e.g., group support, quiet environment). There was also more evidence of parental support with this group. 5/7 Practicing More students completed at least one home practice sheet (seven days of listening to the MF CD and a MF practice like tying their shoes) signed by their parents. Abigail, who expressed a fear of being alone at home and who had a high level of separation anxiety on the Spence pre-test, completed two home practice 
sheets ( 15 days of home practice) and wrote that she did not practice at home by herself because her dad did it with her and helped her concentrate.

While the Practicing More students were more compliant and conscientious- they were easier for the teacher to manage — it is not true that they did not "need" MF as much as other students. Jacinta and Violeta showed high levels of stress in their HRV on the HeartMath program. Jacinta's desire to do well in school may have caused her additional stress. She wrote in her journal that she got angry when she studied hard and got a bad score. When responding to the Spence statement, "I worry that I will do badly at my schoolwork," Kevin and Violeta answered "Always." They talked about being the target of school bullies and wrote 86 excerpts on experiencing negative feelings like anger, anxiety, sadness, frustration, loneliness, and expressed negative feelings about school, teachers, and schoolwork. They also demonstrated a greater awareness that MF can help with negative emotions.

More with Instructor group themes. The MWI group $(n=3)$ represented $20 \%$ of the MF class, so themes in Figures 4 and 6 with 19-20\% or more excerpts from this group represent important themes to some or all of these students: MF as escape, MF as not thinking, Negative feelings, and Visualization, are described in more detail below.

There are four themes with more excerpts from the More with Instructor group than from the other two groups (see Table 6). In the first one, MF as escape (3/7 excerpts), Emma wrote that MF breathing could take her away from the bad things that were happening. Madison wrote, "To do mindfulness all you have to do is calm down have a blank mind. Think somewhere really pretty and breath [breathe]." This concept of $M F$ as not thinking or a blank mind (2/2 excerpts) was only expressed by the More with Instructor group. In response to the initial prompt, Emma said that MF is not thinking about anything, and that having no thoughts would be hard. Aman did not think MF was having a blank mind, but preferred being mindless "because when people mack [make] fun of me and it happens a lot it good to keep a blank mind, so you don't [don't] lissen [listen] to them."

Negative feelings toward school. $4 / 7$ of the excerpts in this theme came from the More with Instructor group. Aman, who wrote that people made fun of him a lot, also wrote that he really wanted to go home and that he wished school wasn't even invented. Emma wrote the other three excerpts, expressing a strong dislike of the school. "What would make me fell [feel] better today is to move and never come to this school. I also want to move away because of kids and all the bad stuff they do. I want to try to stay away from all of the badniss [badness]." 
Visualization. Madison used visualization when she was breathing to help her concentrate and escape from the world. "If you set your mind to it everything around you disapears [disappears]. Then your [you're] in thathappy place of your dream." In Figure 2, Madison drew herself thinking of trees and clouds while listening to music. When I asked Aman if he saw a picture in his head when he concentrated on his breath and if so what it was, Aman answered "yes" and drew a stick figure sitting cross-legged on a cloud with a smile on his face.

Aman showed an ability to concentrate in class and a precision in describing his feelings that did not appear in his writing, a skill that was difficult for him. In his picture, he was the only one that drew himself using a mudra, a finger position used in meditation where the index finger and thumb are pressed together. His teacher gave him a "1" on attentiveness during instruction and he himself wrote that he didn't listen that much. He showed high levels of stress in HeartMath, had a high anxiety score on the Spence pre-test (51), and wrote that "I am afraid of everything." The drawing of his face in Figure 2 with the large eyes and straight mouth looks somewhat anxious and uncertain.

Madison was often defiant and restless in class. In response to the question of whether she thought of herself as a good student, she wrote that she was not good or bad. "I be good when I want and bad when I get mad." She often verbalized that she had problems with "anger management" because of a family member who had died recently. When writing about anger, she said it was hard to control it. "I hope I can control [control] it better." She was rated as a "1" by her teacher in both attentiveness and for practicing MF in class. She had the highest anxiety score on the Spence pre-test in class and also the highest amount of positive change in anxiety and emotional awareness. She and Aman both completed one sheet (7 days) of home practice.

Madison had a great influence on Emma's behavior, writing on one occasion that she helps her friend Emma to be quiet. Both she and Emma were described by the teacher as having off-task or negative behavior one time. The first author observed that Emma often copied the behavior of Madison. Emma wrote, "Most of the time I am good and most of the time I am bad." There is no evidence of parental support (MF practice) for Emma, but she used MF breathing to calm herself down and keep herself from fighting.

In summary, More with Instructor themes were high anxiety, anger, and negative feelings towards other children and school, where they felt harassed or threatened. They were imaginative and kind-hearted students who used visualization and a blank mind to escape from their problems. Perhaps their high levels of stress and sensitivity made it more difficult for them to concentrate on a daily level, and so were less responsive to the classroom teacher 
because she did not have a lot of experience teaching/practicing MF. Other students with similar traits may be receptive to MF, but their teachers will need more training to effectively respond to them.

Practicing Less group themes. The Practicing Less group $(n=5)$ represented 33\% of the MF class. Themes in Figures 4 and 5 with approximately 33\% or more excerpts from this group are Helps with negative emotions, Anger, and Class conflict about MF practice. Below are the themes for which the Practicing Less group had the highest percentage of excerpts (see Figures 7).

Like being clean or looking good. This theme was unique to the Practicing Less group, and especially to Diego, who wrote that he was afraid of having toothpaste on his lip when he went to school and that he wished his clothes were different. In answer to an individual prompt about if it was important to look good, Diego responded yes, "so you don't look ugly." One of Sebastian's unpleasant events was when his shoes got dirty. His feelings and thoughts after this happened were: "My stomach feels funny. I'm sad. I want to punch someone."

Desire to hurt others. While this theme was not unique to the Practicing Less group, they contributed 6/11 excerpts here. Sebastian did not use MF to calm down after his shoes got dirty. When answering a prompt about how he felt now about the unpleasant event he wrote that he still felt like punching someone. Santino wanted to punch someone when they were talking about him, and Victoria felt like hitting someone when she woke up tired. In the theme Negative feelings kid or siblings, the Practicing Less group contributed 7/28 excerpts, but bullying is not mentioned by them. Santino, who wrote four of the excerpts, wrote about being angry when his sister told on him "for no reason" and "when the guys yell at me."

Like playing games on the computer. This was one of the most important themes to the Practicing Less group. While 5/24 excerpts here were from the Practicing More group, the computer games they talked about were the educational math games they played in class. The Practicing Less group also liked these games, but they mostly referenced video games. When asked to describe a moment in which he experienced lovingkindness, Emilio answered by writing that he played Mortal Combat. "I want to play my games." Santino's journal had four references to video games. "I noticed when I play video games it is exciting. I think that video games are cool. I wish I was playing video games right now." Sebastian wrote about video games four times, noticing happy feelings when he was playing, wishing he was playing games "right now," and stating that he could get out of a bad mood by playing his game. Diego (with 3 excerpts) wrote that playing video games would make him happy because he had not played video games in 4 days. 
MF as boring. In an effort to increase students' awareness of the emotions and thoughts surrounding boredom, and also to express support for their current experience, we asked students to describe what the word boring meant to them in their journals. Being restless or unable to sit still, which the first author observed in Sebastian and Diego when she was teaching them how to use the HeartMath program, may have been one reason that some students found MF boring. Sebastian disliked MF more than any of the other students. In his journal, he wrote that "mindfulness" was his unpleasant event. "I hate this, I feel weird in my head, I feel like punching someone." He was also very vocal during class about his feelings of boredom. He wrote, "Boring means to me like I don't like it. It's dumb that's what I think it means to me. It also means to not want to be there and stuff like that."

Some of the students may have written that MF was boring because others around them were saying or writing this. On the last day of the intervention, all of the students sat together in the library drawing pictures and defining MF. Kevin (Practicing More group) wrote that MF class is "relaxing and breathing it is boring but I do like it not that much." This contradicts all of his other journal entries, where he said that he liked MF class, "It is my favorite." Three of the boys sitting around him also wrote that MF was boring.

Dislike MF listening. One reason that students described MF class as boring was that they disliked MF listening. The first author introduced MF listening as giving full attention to sounds like the ringing of the bell. "Listen until the sound stops, and when it stops, raise your hand. What is it like to just listen?" The classroom teacher also had students practice listening skills by watching a video of "soothing Chinese music" and two "beautiful music videos." Then, in another lesson, the first author defined MF listening as Saltzman (2004) did, "Listening to whoever is speaking with your full attention, with your ears, your mind, and your heart" (p. 47). Following suit, the teacher began to review "guidelines" for MF listening much like other behaviors taught in PBSby reviewing them at the beginning of each class period. The first author observed the teacher using the words "MF listening" in class when she wanted students to stop talking (a pleasurable experience) and start listening to instruction (a boring experience). Three students said they would not practice it because it was boring. "No," wrote Emilio (Practicing Less group), " because it is boreing [boring] and it sucks." 
With the exception of Sebastian (who received a "3"), all of the Practicing Less students received a "1" rating from their teacher on attentiveness during instruction. They were not motivated or conscientious students and they responded to the teacher's discipline with extreme negativity. They were frequently described as "off-task" during MF practice and often said that MF was boring. They disliked MF listening, perhaps because it became a classroom management prompt that meant to stop talking and listen to the teacher. They may have disliked MF because they associated it with "being quiet" when they wanted to talk to their friends. They, more than the other groups, expressed a desire to punch or hit other kids, but they did not mention being bullied. They had more feelings of anger toward the teacher than the other groups. They did not describe themselves as good students or smart, except for Diego, who said he was a "little smart." They liked playing video games because they were "cool" and "exciting." They liked sports and responded positively to the lesson on MF and the Lakers, writing that MF helps with playing sports by increasing concentration and calmness. While this group often strongly expressed dissatisfaction or displeasure with MF class, they also wrote 43 excerpts on the benefits of MF practice.

\section{Discussion}

Below we will first summarize the quantitative and qualitative results. Then we will use these findings to provide several recommendations for future MF interventions in school settings.

\section{Quantitative Results: Emotion Regulation and Academic Performance}

Two of our study goals were to investigate the impact of MF training on emotion regulation and academic performance in children. Our quantitative results suggest that based on teacher ratings, students who consistently practice MF breathing are more mindful, have more positive attitudes toward academic subjects, and are better able to regulate their attention.

Our quantitative results also showed high correlations between the child MF measure (CAMM), the emotion awareness questionnaire (EAQ) and the child anxiety measure (Spence), suggesting a relationship between high levels of mindfulness, emotional awareness, and anxiety. In other words, higher levels of MF and emotional awareness were consistent with a greater awareness of anxiety during a very stressful and busy time - the last quarter of the school year. MF class was cancelled 18 times out of a possible 45 sessions. Although MF has been shown to be a potent intervention, wherein a single 10-20-minute session can impact cognitive processing (Ostafin \& Kassman, 2012; Wenk-Sormaz, 2005), and participants in the present study practiced MF for far more than a single 20-minute session, it may be helpful to other educators and researchers to consider the timing of their MF 
intervention in a public school setting — earlier in the school year might be better. On fourteen of these missed days, MF class was cancelled because students had to take the state standardized test. These test sessions took the entire day and children had to also miss recess and eat lunch in their classrooms. Mean difference scores on the Reading Attitude Inventory (RAI; post-test minus pre-test) across all students was -.43 ( $p>.05)$. Students disliked reading more after intensive standardized state testing than before. Student scores on the district standardized reading test also indicated test burnout; mean scores decreased from pre-test to post-test $\left(p>.05\right.$; experimental $M_{d i f}=-5$; control $\left.M_{d i f}=-3\right)$. These results indicate that students' positive attitudes toward school and their subsequent academic performance may have decreased because they became more aware of their stress in that environment.

\section{Qualitative Results}

We confirmed that there are a sample of students who are not receptive to MF training. This occurred even though the consent process eliminated children and parents who were not interested in participating. MF interventions do not work well on non-receptive students. Also, these students can "poison the well" and impair MF learning in those students who are receptive.

Analysis of journal excerpts revealed differing themes from children who were receptive or resistant to the treatment. These themes provided clues as to the children's attitudes and perceptions toward MF. Themes important to the whole group were MF as suppressing bad thoughts, MF as beneficial, Helps with negative emotions, and MF as breathing. All of the students liked MF eating and all of the students expressed Anger as a theme.

Themes that were predominant in the Practicing More group were Like being good, Like schoolwork or learning, Like teacher, Like MF, Positive self-esteem, Lovingkindness, compassion, being good or nice. They seemed to have more positive attitudes towards school, themselves, and others. They also defined MF as expressing or "feeling" or listening to the heart, as a practice or goal or doing it "right," as fun, and as being/feeling quiet. However, they felt bullied by others as indicated in the theme Negative feelings children or siblings and they were not happy that the Practicing Less group were often disruptive during MF training, as indicated in the theme, Class conflict about MF practice.

Themes that were predominant to the More with Instructor group were the use of MF as escape from the stresses of their life, including their Negative feelings toward school. These students also tended to use 
Visualization while meditating and may have found MF hard because they thought of it as not thinking or a blank mind.

Themes predominant to the Practicing Less group were negative feelings toward themselves and others, including a Desire to hurt others, Negative feelings toward teacher or coach, and Low self-esteem or "I'm bad" or "stupid." They also had negative feelings toward MF, including MF as boring, Like mindlessness, and Dislike MF listening. They Like being clean and looking good and playing games on computers.

In summary, the whole group found positive benefits of MF training —it helped with negative emotions and increased positive feelings. The Practicing More group seemed to enjoy school or learning more, liked being kind to others, were more responsive to the teacher, and were disturbed by the other children's negative attitudes toward MF. The More with Instructor (MWI) group had more negative feelings toward school, wanted to use MF as an escape from negative feelings and situations, and used visualization during MF practice. The Practicing Less group had more negative feelings toward MF and themselves, but, after a lesson on how the Lakers used MF to prepare for games, these resistant students also recognized that MF could help with sports. This group also liked playing video games.

\section{Study Limitations}

First, the relatively small sample size and the primary reliance on qualitative data analysis may limit generalization of the results. Second, we cannot rule out that participants may have been subject to demand characteristics. Although we encouraged them to talk and write about their negative experiences, students may have written things they thought they were "supposed" to write. Finally, because the first author was both an instructor and the data analyst, bias may have entered into the analysis. However, we found strong patterns in the data that indicate traits of students who are resistant or receptive to MF. An important goal for future research is to verify that these traits generalize to larger samples with different socioeconomic and personality characteristics.

\section{Directions for Future Research}

Given the consistent trends towards personality differences between receptive and non-receptive students found in the journal entries, it would be valuable to follow-up on this finding by using pre- and post-test measures on Big Five traits, sensation seeking, animosity, video game addiction, and boredom. In addition, it would be useful to conduct formalized observations of students in a classroom MF intervention using checklists of the aforementioned traits. Do the formal observations correlate with the self-report measures? 
Another important direction for future research is investigating means of increasing motivation and receptiveness towards MF. In particular, do game-based MF interventions ameliorate chronic boredom and animosity and increase arousal in sensation seeking children? Action video games are already being designed that use biometric information (e.g., Heart Rate Variability) to manipulate a player's emotional state to enhance feelings of horror. For example, in Please Biofeed the Zombies (Dekker \& Champion, 2007), a player's heartrate affects their avatar's speed, increases or decreases background music volume, and triggers game effects like screen filters—red for a fast heartbeat, white for calmness. There are also advantages for controlling excitement levels in this game. A player can see through walls and become invisible if they are able to lower their galvanic skin response. While game developers may exploit biometrics in order to increase game sales, thoughtful researchers could design games that sensation seeking individuals find exciting while simultaneously motivating them to learn how to regulate their energy levels using MF practices.

\section{Practical Applications}

Studies of MF training with children have demonstrated benefits of MF including the increase of attention and emotion regulation skills. Because schools are under enormous pressure to increase standardized test scores and demonstrate academic proficiency in all of their students, MF training offers a solution that can increase student performance while simultaneously lowering stress levels for students. Our study offers the following applications for parents, counselors, and educators.

Use traits to identify resistant students. The five factor personality model (Big Five: Giluk, 2009) can be used to identify, understand, and treat students who are consistently resistant and disruptive during classroom MF practice. Students who are disruptive because they find it difficult to sit still may need to have more MF movement incorporated into the routine. Some students may enjoy losing self-awareness more than gaining it (e.g., the students in our study that preferred "mindlessness"), so lessons on the relationship between flow and MF can be taught. Flow is defined as an altered state of consciousness that spontaneously arises when absorbed into a challenging, but enjoyable activity like playing sports or computer games. Because MF involves the maintenance of moment-to-moment awareness, it may not occur simultaneously with flow, but MF may make it more possible—by cleaning out mental chatter and developing concentration skills - to enter flow states (Sheldon, Prentice, \& Halusic, 2014). 
Explore game-based treatments. Students who demonstrate reactant boredom, a type of boredom that is highly unpleasant and is connected with a strong motivation to escape the perceived cause of the boredom (Goetz et al., 2014) should be taken out of the classroom and treated separately. If these students also exhibit the trait of sensation seeking and enjoy playing video games, it may be worthwhile to explore a game-based MF treatment. Bowman and Tamborini (2012) induced boredom or stress in participants before they took mood measures and then had them play a computer game for a few minutes before completing another set of mood measures. The researchers found that computer games positively affected mood repair more in bored subjects than in stressed subjects. They hypothesized that this was because the games increased arousal and interfered with rumination.

McGonigal (2011) suggested that we use what we know about game design to improve our daily lives and solve real-world problems. She gave an example of an alternate reality game called Chore Wars, where players create quests based on household chores and play with roommates or family members. Participants create avatars who gain experience points, virtual treasure, avatar power-ups, and real-world awards (e.g., additional allowance for children) by completing chores--the more unpleasant the chore, the more points are earned. This game could be adapted by a counselor or resource teacher in order to motivate a student to complete difficult chores in school— e.g., completing math problems, not calling out in class. The student could customize the adventure and MF practices could be integrated into the game as another way to earn points.

Journey to Wild Divine (www.wilddivine.com) is a computer game that uses electronic equipment to provide feedback to players on their Skin Conductance Level and Heart Rate Variability. Players have to learn how to regulate their energy levels in order to navigate through areas of the game world and overcome certain challenges. For example, in order to lower an arrow until it is pointing directly at the bullseye, a player has to calm her energy down by taking long, slow breaths. However, if the arrow moves too far down and needs to be raised, the player has to raise her energy by breathing quickly. This game may be an effective way for some resistant students to learn MF practices, but it lacks the fast-paced excitement that sensation seeking children may be craving.

School-wide implementation. To effectively support the implementation of MF, a school-wide commitment to a daily ten to fifteen-minute breathing practice is advised. During this time, phones could be diverted, support staff should participate, and visitors should be kept in the office so that classes can meditate without interruption. MF practice would need to continue even during standardized testing; in fact, this is a time when students need it the most. MF training could be extended on a weekly basis to include a time when teachers 
nonjudgmentally support children's expression of their thoughts and feelings through writing, discussion groups, or artistic expression. This opportunity for reflective abstraction may help to reverse the steady decline in creative thinking caused in part by the standardized testing movement that has sterilized the classroom with the drill exercises of rote learning and eliminated many opportunities for releasing creative energy at school (Kim, 2011).

MF can be integrated into the curriculum. Another implication of this study is that MF serves as a protective factor, helping students who practice MF to preserve or improve positive attitudes toward academics. Scores on the Reading Attitude Inventory were highly correlated with the teacher's ratings of student MF practice and demonstrated that students who practiced more maintained or improved their attitudes toward reading (Practicing More $M_{d i f f}=-.71$, More with Instruction and Practicing Less group $M_{\text {diff }}=-4.0$ ). Another implication is that it is important to teach students strategies for calming themselves down and increasing their self-confidence while they are in the process of learning. Some of the most effective lessons in the intervention incorporated reading, writing, and MF awareness of emotions (e.g., reading and writing about children's literature devoted to the topic of anger). The detailed descriptions and strong voice in their journal excerpts demonstrated that both writing and MF skills can be developed simultaneously. The lesson on MF and the Lakers also showed the importance of choosing reading materials that are appropriate for a number of reasons beyond the necessary one of correct reading level; reading passages need to stimulate both intellectual and emotional growth. The Lakers article was especially relevant because it demonstrated to students that men — and not just the women teachers at their school—also practiced MF in order to become better athletes. This is another implication of the study —it is important for MF instructors to find role models of both sexes who practice MF and who are respected and well-liked by the students.

Provide strong incentives for teachers to undergo MF training. Teacher implementation of MF is critically important to the success of MF research in schools. Instructors who have very limited experience with MF practice can bring an attitude of judgment into their teaching (e.g., "It is not okay to say that MF is boring"), thereby creating negative attitudes toward MF in their students. It is important to model MF instructional techniques, observe MF instruction, and offer constructive feedback. It is also necessary to help teachers understand the similarities and differences between MF training and behavioral support programs like PBS. Modeling of MF instruction was provided in this study, and the teacher completed a basic MF course. Limited training might not have been enough. Future studies should require MF teachers to complete a comprehensive course that includes 
instruction in establishing a personal MF practice, modeling of teaching methods, supervision of one-on-one MF sessions with children, and weekly observations and evaluations of classroom sessions.

\section{Conclusion}

In conclusion, we found that some students were receptive to MF while others were resistant, confirming previous findings. Children receptive to MF treatment exhibited the traits of openness to experience, agreeableness, conscientiousness, and conformity to the teacher's ideas and expectations. Resistant children exhibited traits of boredom, sensation seeking, animosity, and conformity to peer pressure. We described possible ways of dealing with resistant children, including incorporating more movement into MF training and using game-based treatments.

Even though some children who have a high need for emotion regulatory training may be extremely resistant and disruptive during classroom-based MF treatments, teaching MF can still be a positive experience for students. After the study had concluded, the experimental teacher (not a member of the research team) in this study wrote, "I am still convinced that mindfulness is beneficial to students. In hindsight, these are a couple of things I would do differently. 1) Teaching a lesson and practicing the breathing requires a minimum of 30 to 45 minutes per day. 2) The most difficult students to reach would benefit from one-on-one practice" (personal communication, July 24, 2015).

It is also important to note that, while some of the children were mostly resistant to MF, they also said positive things about MF and found some benefit from the intervention. All of the students in this study wrote about the benefits of MF - that it helps with negative emotions like anger and fear and that it brings positive feelings of happiness, peace, and relaxation. Additionally, the last drawing and words of Sebastian - the most resistant and disruptive participant — offer a ray of hope that MF can be still be an effective intervention for these students. On the last day of the intervention, Sebastian drew a picture of himself practicing MF. In it, he is lying on the ground, his hands behind his head, a smile on his face. In answer to the prompt, "Tell your parents what mindfulness is," he wrote this response: "It's breathing very slow and paying attention to your breath. And realy [really] coming [calming] down. It's also giving peace."

All procedures performed in studies involving human participants were in accordance with the ethical standards of the institutional and/or national research committee and with the 1964 Helsinki declaration and its later amendments or comparable ethical standards. 
Author Contributions:

J. R. and E. R. designed and wrote the study. P. K. contributed to data collection, design of the E-Prime measures, and the coding process. R. H. contributed to the statistical analysis, and N. G. contributed to the design of the eprime measures. K.B. performed final edits. 


\section{References}

Averill, J. B. (2013). Content synopsis for basic qualitative inquiry. Publisher: Author.

Boud, D. (2001). Using journal writing to enhance reflective practice. New Directions for Adult and Continuing Education, 90, 9-18. doi:10.1002/ace.16

Bowman, N. D. \& Tamborini, R. (2012). Task demand and mood repair: The intervention potential of computer games. New Media and Society, 14(8), 1339-1357. doi:10.1177/1461444812450426

Broderick, P. C., \& Metz, S. (2009). Learning to BREATHE: A pilot trial of a mindfulness curriculum for adolescents. Advances in School Mental Health Promotion, 2(1), 35-46. doi: 10.1080/1754730x. 2009.9715696

Campion, J., \& Rocco, S. (2009). Minding the mind: The effects and potential of a school-based meditation program for mental health promotion. Advances in School Mental Health Promotion, 2(1), 47-55. doi:10.1080/1754730x.2009.9715697

Chiesa, A., Calati, R., \& Serretti, A. (2011). Does mindfulness training improve cognitive abilities? A systematic review of neuropsychological findings. Clinical Psychology Review, 31(3), 449-464. doi:10.1016/ j.cpr.2010.11.003

Cohen, J. D., Barch, D. M., Carter, C., \& Servan-Schreiber, D. (1999). Context-processing deficits in schizophrenia: Converging evidence from three theoretically motivated cognitive tasks. Journal of Abnormal Psychology, 108(1), 120-133. doi:10.1037/0021-843X.108.1.120

Corcoran, K. M., Farb, N., Anderson, A., \& Segal, Z. V. (2010). Mindfulness and emotion regulation: Outcomes and possible mediating mechanisms. In King, A. M. \& Sloan, D. M. (Eds.), Emotion regulation and psychopathology: A transdiagnosic approach to etiology and treatment (339-355). New York: Guilford Press.

Davidson, R. J., Kabat-Zinn, J., Schumacher, J., Rosenkranz, M., Muller, D., Santorelli, S. F., . . Sheridan, J. F. (2003). Alterations in brain and immune function produced by mindfulness meditation. Psychosomatic Medicine, 65(4), 564-570. doi:10.1097/01.PSY.0000077505.67574.E3

Davidson, R. J. (2010). Empirical explorations of mindfulness: Conceptual and methodological conundrums. Emotion, 10(1), 8-11. doi:10.1037/a0018480 
Dedoose Version 6.1.9, web application for managing, analyzing, and presenting qualitative and mixed method research data (2015). Los Angeles, CA: SocioCultural Research Consultants, LLC (www.dedoose.com).

Dekker, A., \& Champion, E. (2007). Please biofeed the zombies: Enhancing the gameplay and display of a horror game using biofeedback. Paper presented at the Digital Games Research Association (DiGRA) 2007 International Conference, Tokyo, Japan. Retrieved July 5, 2015, from http://www.cs.tufts.edu/ jacob/250pbi/Please_biofeed_the_zombies.pdf

Denzin, N. K., \& Lincoln, Y .S. (1994). The Sage handbook of qualitative research. Thousand Oaks, CA: Sage.

Evans, G. W. \& English, K. (2002).The environment of poverty: Multiple stressor exposure, psychophysiological stress, and socioemotional adjustment. Child Development, 73(4), 1238-1248. Retrieved from http://www.jstor.org/stable/3696282

Fisher, R. (2006). Still thinking: The case for meditation with children. Thinking Skills and Creativity, 1(2), 146151. doi:10.1016/j.tsc.2006.06.004

Franceschini, S., Gori, S., Ruffino, M., Viola, S., Molteni, M., \& Facoetti, A. (2013). Action video games make dyslexic children read better. Current Biology, 23(6), 462-466. doi:10.1016/j.cub.2013.01.044

Giluk, T. L. (2009). Mindfulness, Big Five personality, and affect: A meta-analysis. Personality and Individual Differences, 47(8), 805-811. doi:10.1016/j.paid.2009.06.026

Goetz, T., Frenzel, A. C., Hall, N. C., Nett, U. E., Pekrun, R., \& Lipnevich, A. A. (2014). Types of boredom: An experience sampling approach. Motivation and Emotion, 38(3), 401-419. doi: 10.1007/s11031-013-9385-y.

Greco, L. A., Baer, R. A., \& Smith, G. T. (2011). Assessing mindfulness in children and adolescents: Development and validation of the Child and Adolescent Mindfulness Measure (CAMM). Psychological Assessment, 23(3), 606-614. doi:10.1037/a0022819

Hamama, L. \& Ronen, T. (2009). Children's drawings as a self-report measurement. Child and Family Social Work, 14(1), 90-102. doi:10.1111/j.1365-2206.2008.00585.x.

Hopperstad, M. H. (2010). Studying meaning in children's drawings. Journal of Early Childhood Literacy, 10(4), 430-452. doi:10.1177/1468798410383251

Hutcherson, C. A., Seppala, E. M., \& Gross, J. J. (2008). Loving-kindness meditation increases social connectedness. Emotion, 8(5), 720-724. doi:10.1037/a0013237

Kabat-Zinn, J. (1994). Wherever you go, there you are: Mindfulness meditation in everyday life. New York: 
Hyperion.

Kim, K. H. (2011). The creativity crisis: The decrease in creative thinking scores on the Torrance Tests of Creative Thinking. Creativity Research Journal, 23(4), 285-295. doi:10.1080/10400419.2011.627805

Lewis, J. (1979). A reading attitude inventory for elementary school pupils. Educational and Psychological Measurement, 39(2), 511-513. doi:10.1177/001316447903900236

Majumdar, M., Grossman, P., Dietz-Waschkowski, B., Kersig, S., \& Walach, H. (2004). Does mindfulness meditation contribute to health? Outcome evaluation of a German sample. Journal of Alternative and Complementary Medicine, 8(6), 719. doi:10.1089/10755530260511720

Manly, T., Anderson, V., Nimmo-Smith, I., Turner, A., Watson, P., \& Robertson, I. H. (2001). The differential assessment of children's attention: The Test of Everyday Attention for Children (TEA-Ch); Normative sample and ADHD performance. Journal of Child Psychology and Psychiatry, 42(8), 1065-1081. doi: 10.1017/S0021963001007909

Merriam, S. B. (2009). Qualitative research: A guide to design and implementation. San Francisco, CA: JosseyBass.

McGonigal, J. (2011). Reality is broken. New York: Penguin Press.

Napoli, M., Krech, P. R., \& Holley, L. C. (2005). Mindfulness training for elementary school students: The Attention Academy. Journal of Applied School Psychology, 21(1), 99-125. doi:10.1300/J370v21n01_05

Napoli, M. (2004). Mindfulness training for teachers: A pilot program. Journal of Evidence-Based Complementary and Alternative Medicine, 9(1), 31-42. doi: 10.1177/1076167503253435

Ortner, C. N. M., Kilner, S. J., \& Zelazo, P. D. (2007). Mindfulness meditation and reduced emotional interference on a cognitive task. Motivation and Emotion, 31, 271-283. doi:10.1007/s11031-007-9076-7

Ostafin, B. D. \& Kassman, K. T. (2012). Stepping out of history: Mindfulness improves insight problem solving. Consciousness and Cognition, 21(2), 1031-1036. doi:10.1016/j.concog.2012.02.014

Rieffe, C., Oosterveld, P., Miers, A. C., Terwogt, M. M., \& Ly, V. (2008). Emotion awareness and internalizing symptoms in children and adolescents: The Emotion Awareness Questionnaire revised. Personality and Individual Differences, 45(8), 756-761. doi:10.1016/j.paid.2008.08.001

Rosaen, C., \& Benn, R. (2006). The experience of Transcendental Meditation in middle school students: A qualitative report. Explore: The Journal of Science and Healing, 2(5), 422-425. doi:10.1016/j.explore. 
2006.06.001

Roth, B., \& Robbins, D. (2004). Mindfulness-Based Stress Reduction and health-related quality of life: Findings from a bilingual inner-city patient population. Psychosomatic Medicine, 66(1), 113-123. doi:10.1097/ 01.PSY.0000097337.00754.09

Saltzman, A. (2007). Still quiet place: Mindfulness for young children [CD]. Producer: Author.

Saltzman, A. (2004). Practices for children and adolescents to discover peace and happiness. Publisher: Author.

Sarason, I. G. (1978). Test Anxiety Scale: Concept and research. In Spielberger, C. D. \& Sarason, I. E. (Eds.), Stress And Anxiety, Vol.5. New York: Hemisphere Publishing Corporation.

Semple, R. J., Reid, E. F. G., \& Miller, L. (2005). Treating anxiety with mindfulness: An open trial of mindfulness training for anxious children. Journal of Cognitive Psychotherapy, 19(4), 375-392. doi:10.1891/ jcop.2005.19.4.379

Sheldon, K. M., Prentice, M., \& Halusic, M. (2014). The experiential incompatibility of mindfulness and flow absorption. Social Psychological and Personality Science, 6(3), 276-283. doi:10.1177/1948550614555028

Simon, J. R. \& Small, A. M. (1969). Processing auditory information: Interference from an irrelevant cue. Journal of Applied Psychology, 53(5), 433-435. doi:10.1037/h0028034

Spence, S. H. (1998). A measure of anxiety symptoms among children. Behaviour Research and Therapy 36(5), 545-566. doi:10/1016/S0005-7967(98)00034-5

Sturner, R. A., Rothbaum, F., Visintainer, M., \& Wolfer, J. (1980). The effects of stress on children's human figure drawings. Journal of Clinical Psychology, 36(1), 324-331. doi:10.1002/1097-4679(198001)

Tang, Y, \& Posner, M. L. (2009). Attention training and attention state training. Trends in Cognitive Science 13(5), 222-227. doi:10.1016/j.tics.2009.01.009

Ullmann, R. K., Sleator, E. K., \& Sprague, R. L. (1997). ADD-II Comprehensive Teacher Rating Scale (ACTeRS), Champaign, IL: MetriTech. Inc.

Unsworth, N., Heitz, R. P., Schrock, J. C., \& Engle, R. W. (2005). An automated version of the operation span task. Behavior Research Methods, 37(3), 498-505. doi:10.3758/BF03192720

Varela, F.J. (1996). Neurophenomenology: A methodological remedy for the hard problem. Journal of Consciousness Studies, 3(4), 330-249.

Waters, L., Barsky, A., Ridd, A., \& Allen, K. (2015). Contemplative education: A systematic, evidence-based 
review of the effect of meditation interventions in schools. Educational Psychology Review, 27, 103-134. doi:10.1007/s10648-014-9258-2

Wenk-Sormaz, H. (2005). Meditation can reduce habitual responding. Alternative Therapies in Health and Medicine, 11(2), 42-58. 


\section{Appendix}

Writing Prompts (appear in the order presented in the intervention)

*Prompts generated by the classroom teacher

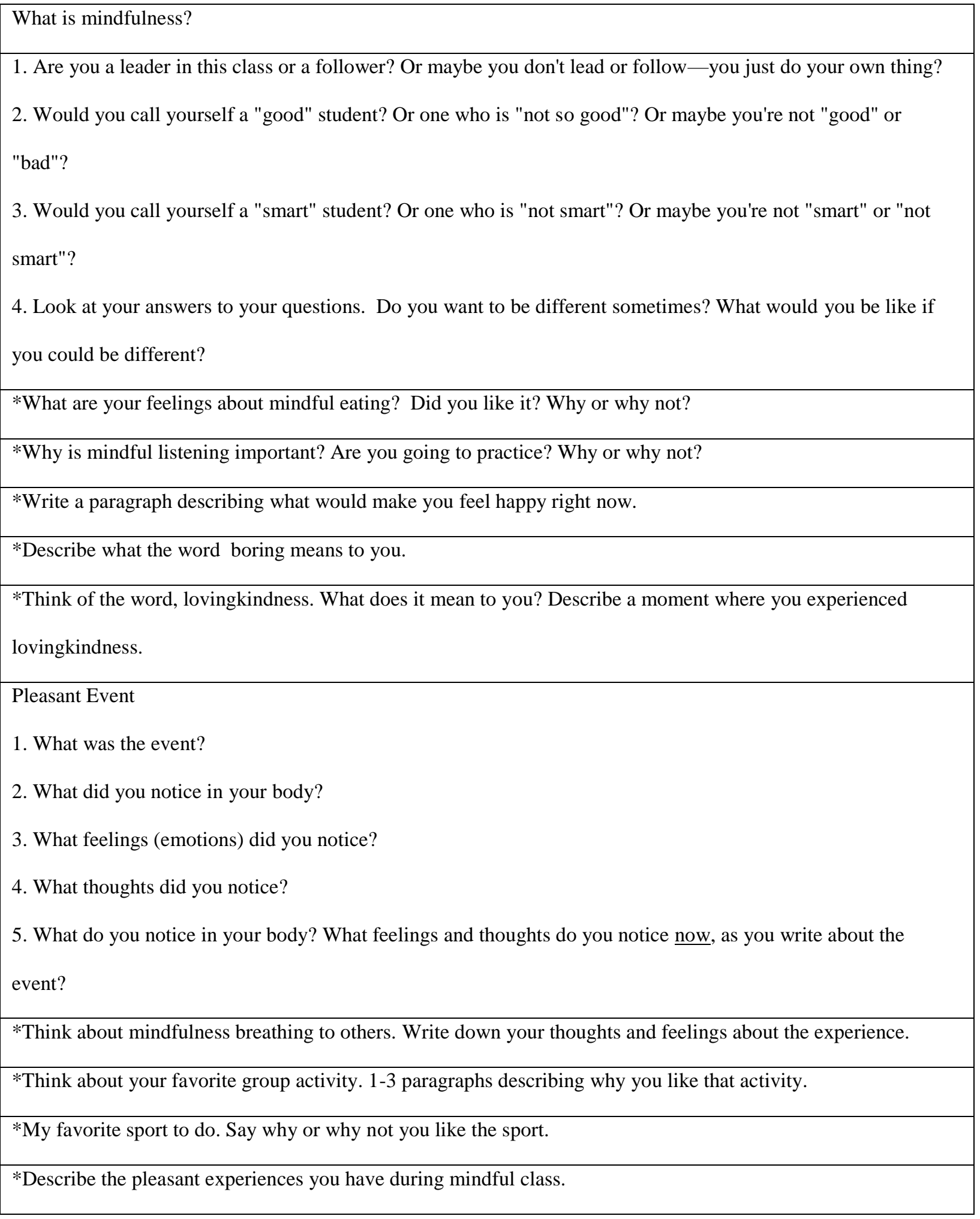


*Describe what choices you can make to turn negative feelings into happy feelings.

Describe some things that make you angry. Write how mindfulness breathing can help you deal with angry emotions.

*What can you do when the grouchies take hold? How can you help yourself get out of a bad mood?

Mindfulness and the Lakers

1. What do you think being "in the zone" means?

2. How does mindfulness help basketball players?

3. How can mindfulness help you play sports?

4. How can you be a mindfulness warrior?

Unpleasant Event

1. What was the event?

2. What did you notice in your body?

3. What feelings (emotions) did you notice?

4. What thoughts did you notice?

5. What do you notice in your body? What feelings and thoughts do you notice now, as you write about the event?

*When you think of "gossip" do you get a kind or unkind feeling? Describe an experience where gossip has helped or hurt you.

*Do you prefer to be mindful or mindless? Describe how and why it makes you feel happy, calm, and relaxed.

*Think about some optimistic thoughts regarding your $4^{\text {th }}$ grade learning experience. Describe them in a paragraph.

*Optimistic/Pessimistic Thoughts

1. Problem

2. Optimistic Thought Bubble

3. Pessimistic Thought Bubble

1. Tell your parents what mindfulness is. Write 3 sentences.

2. When is a good time to practice mindfulness? 
Table 1

Summary of dependent measures

\begin{tabular}{lllc}
\hline \multicolumn{1}{c}{ Measure } & \multicolumn{1}{c}{ Citation } & Ability Measured & Time Points \\
\hline $\begin{array}{l}\text { Automated version of the } \\
\text { Operation Span (AOspan) }\end{array}$ & $\begin{array}{l}\text { Unsworth, Heitz, Schrock, \& } \\
\text { Engle, 2005 }\end{array}$ & Working memory & 5 \\
\hline $\begin{array}{l}\text { AX Continuous Performance Test } \\
\text { (AXCPT) }\end{array}$ & $\begin{array}{l}\text { Cohen, Barch, Carter, \& Servan- } \\
\text { Schreiber,1999 }\end{array}$ & Selective attention & 5 \\
\hline The Simon task & Simon \& Small, 1969 & Selective attention & 5 \\
\hline $\begin{array}{l}\text { The Child and Adolescent } \\
\text { Mindfulness Measure (CAMM) }\end{array}$ & Greco, Baer, \& Smith, 2011 & $\begin{array}{l}\text { MF attention and } \\
\text { awareness }\end{array}$ & 2 \\
\hline $\begin{array}{l}\text { The Spence Children's Anxiety } \\
\text { Scale (Spence) }\end{array}$ & Spence, 1998 & $\begin{array}{l}\text { Identifies anxiety } \\
\text { symptoms }\end{array}$ & 3 \\
\hline $\begin{array}{l}\text { The Emotion Awareness } \\
\text { Questionnaire (EAQ) }\end{array}$ & Rieffe, Oosterveld, Miers, & $\begin{array}{l}\text { Measures emotion } \\
\text { awareness }\end{array}$ \\
\hline $\begin{array}{l}\text { The Reading Attitude Inventory } \\
\text { (RAI) }\end{array}$ & Meerum Terwogt, \& Ly, 2008 & $\begin{array}{c}\text { Assesses reading } \\
\text { attitudes }\end{array}$ & 2 \\
\hline
\end{tabular}

Note: Time points: Times the participants took the measure. 
Table 2

Summary of group means on difference t-tests (Time 1 subtracted from Time 5).

\begin{tabular}{lccc}
\multicolumn{1}{c}{ Measure } & Test & Group & Mean Difference Score \\
\hline $\begin{array}{l}\text { Automated version of the } \\
\text { Operation Span (AOspan) }\end{array}$ & & Experimental & 2.80 \\
\hline AX Continuous Performance & Response Times & Control & 2.69 \\
Test (AXCPT) & (RTs) & Cxperimental & $-61 \mathrm{~ms}$ \\
\hline AX Continuous Performance & \multirow{2}{*}{ Accuracy } & Experimental & $-77 \mathrm{~ms}$ \\
Test (AXCPT) & \multirow{2}{*}{ RTs } & Control & -.011 \\
The Simon task & Accuracy & Experimental & .004 \\
\hline The Simon task & & Control & $-20 \mathrm{~ms}$ \\
& & Experimental & $-4 \mathrm{~ms}$ \\
\hline The Child and Adolescent & Control & .03 \\
Mindfulness Measure & & Experimental & .01 \\
(CAMM) & & Control & -4.20 \\
\hline The Spence Children's Anxiety & & -1.23 \\
Scale (Spence) & & Experimental & -7.67 \\
\hline The Emotion Awareness & Control & -5.62 \\
Questionnaire (EAQ) & Experimental & -6.13 \\
\hline The Reading Attitude & Control & 1.38 \\
Inventory (RAI) & Experimental & -2.47 \\
\hline
\end{tabular}


Table 3

Summary of group means (Practicing More vs. More with Instructor (MWI) and Practicing Less Students)

\begin{tabular}{lccc}
\multicolumn{1}{c}{ Measure } & Test & Group & Mean \\
\hline Automated version of the & & Practicing More & 5.43 \\
Operation Span (AOspan) & & MWI and Practicing Less & 0.50 \\
\hline AX Continuous Performance & Response Times & Practicing More & $-.58 \mathrm{~ms}$ \\
Test (AXCPT) & (RTs) & MWI and Practicing Less & $-.63 \mathrm{~ms}$ \\
\hline AX Continuous Performance & \multirow{2}{*}{ Accuracy } & Practicing More & 0.002 \\
Test (AXCPT) & \multirow{2}{*}{ RTs } & MWI and Practicing Less & -.024 \\
\hline The Simon task & \multirow{2}{*}{ Accuracy } & PWI and Practicing Less & -0.24 \\
& & Practicing More & -0.16 \\
\hline The Simon task & & MWI and Practicing Less & 0.05 \\
& & Practicing More & 0.008 \\
\hline The Child and Adolescent & MWI and Practicing Less & -2.0 \\
Mindfulness Measure & & -6.13 \\
(CAMM) & & Practicing More & -6.86 \\
\hline The Spence Children's Anxiety & & MWI and Practicing Less & -8.38 \\
Scale (Spence) & Practicing More \\
\hline The Emotion Awareness & MWI and Practicing Less & -3.71 \\
Questionnaire (EAQ) & Practicing More & -8.25 \\
\hline The Reading Attitude & MWI and Practicing Less & -0.71 \\
Inventory (RAI) & & -4.0 \\
\hline
\end{tabular}

Note: See note under Table 4 for explanation of Practicing More, MWI, and Practicing Less groups. 
Figure 1

A simplified timeline of study events.

\begin{tabular}{|c|c|c|c|c|c|}
\hline Experimental Group & $\begin{array}{c}\text { MF } \\
\text { Training }\end{array}$ & $\begin{array}{c}\text { MF } \\
\text { Training } \\
\end{array}$ & \begin{tabular}{|c|} 
MF \\
Training \\
\end{tabular} & \begin{tabular}{|c|} 
MF \\
Training
\end{tabular} & $\begin{array}{c}\text { MF } \\
\text { Training } \\
\end{array}$ \\
\hline Control Group & $\begin{array}{l}\text { Quiet } \\
\text { Time }\end{array}$ & $\begin{array}{l}\text { Quiet } \\
\text { Time }\end{array}$ & $\begin{array}{l}\text { Quiet } \\
\text { Time }\end{array}$ & $\begin{array}{l}\text { Quiet } \\
\text { Time }\end{array}$ & $\begin{array}{l}\text { Quiet } \\
\text { Time }\end{array}$ \\
\hline
\end{tabular}


Figure 2

Children's Drawings of Themselves Practicing MF
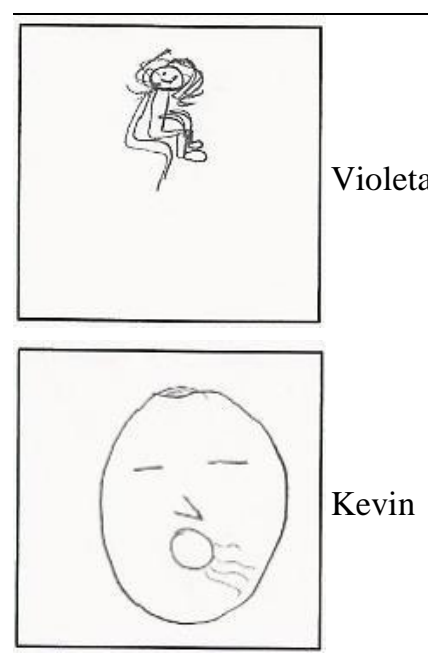

Kevin

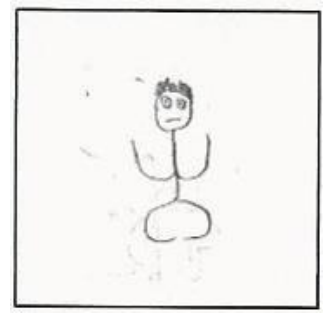

Ethan

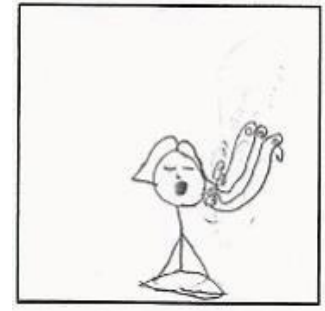

Abigail

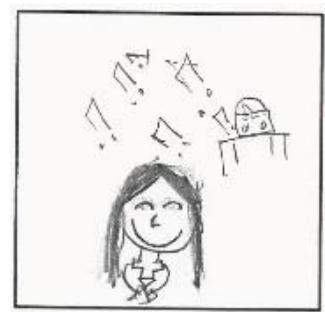

Ashley
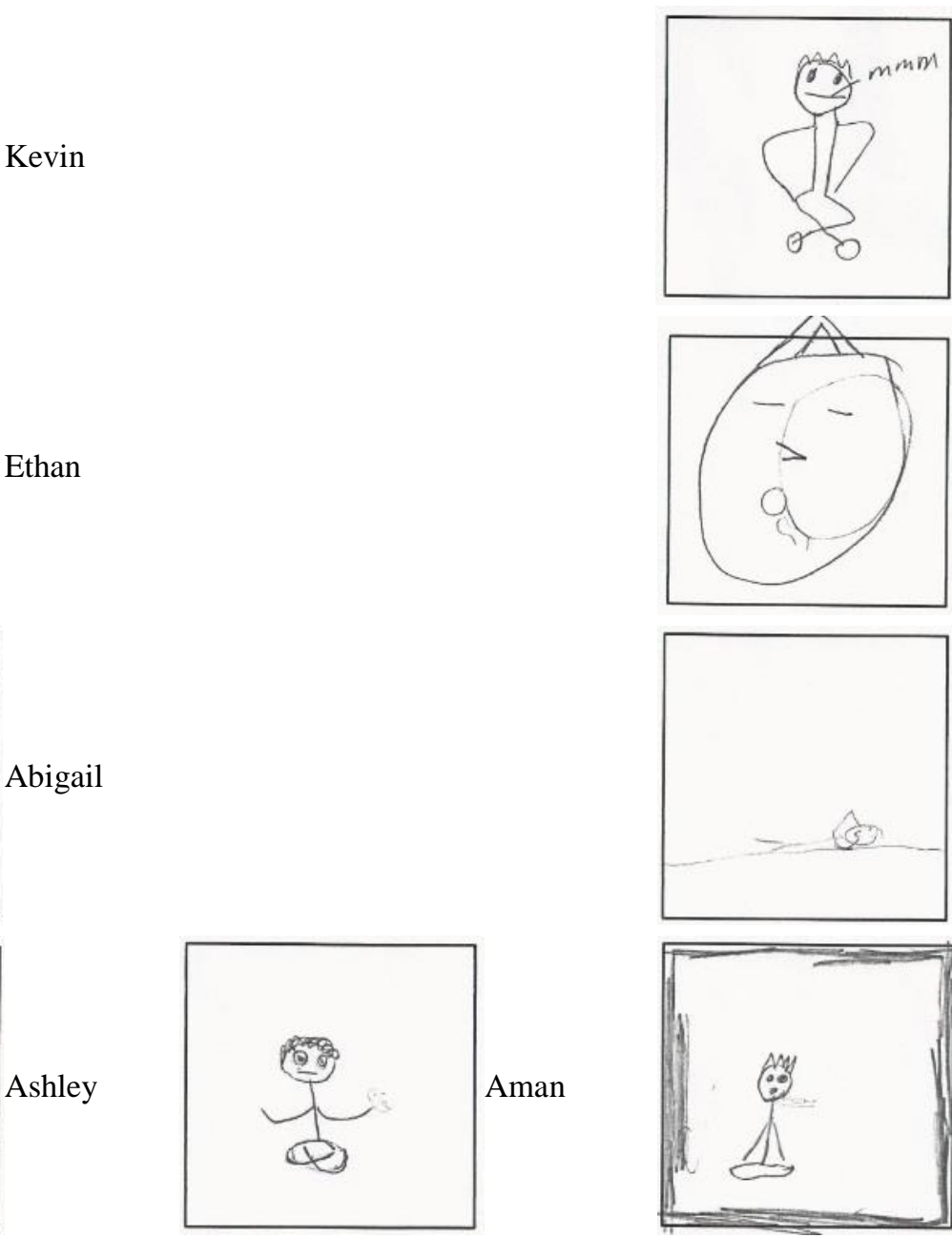

Victoria
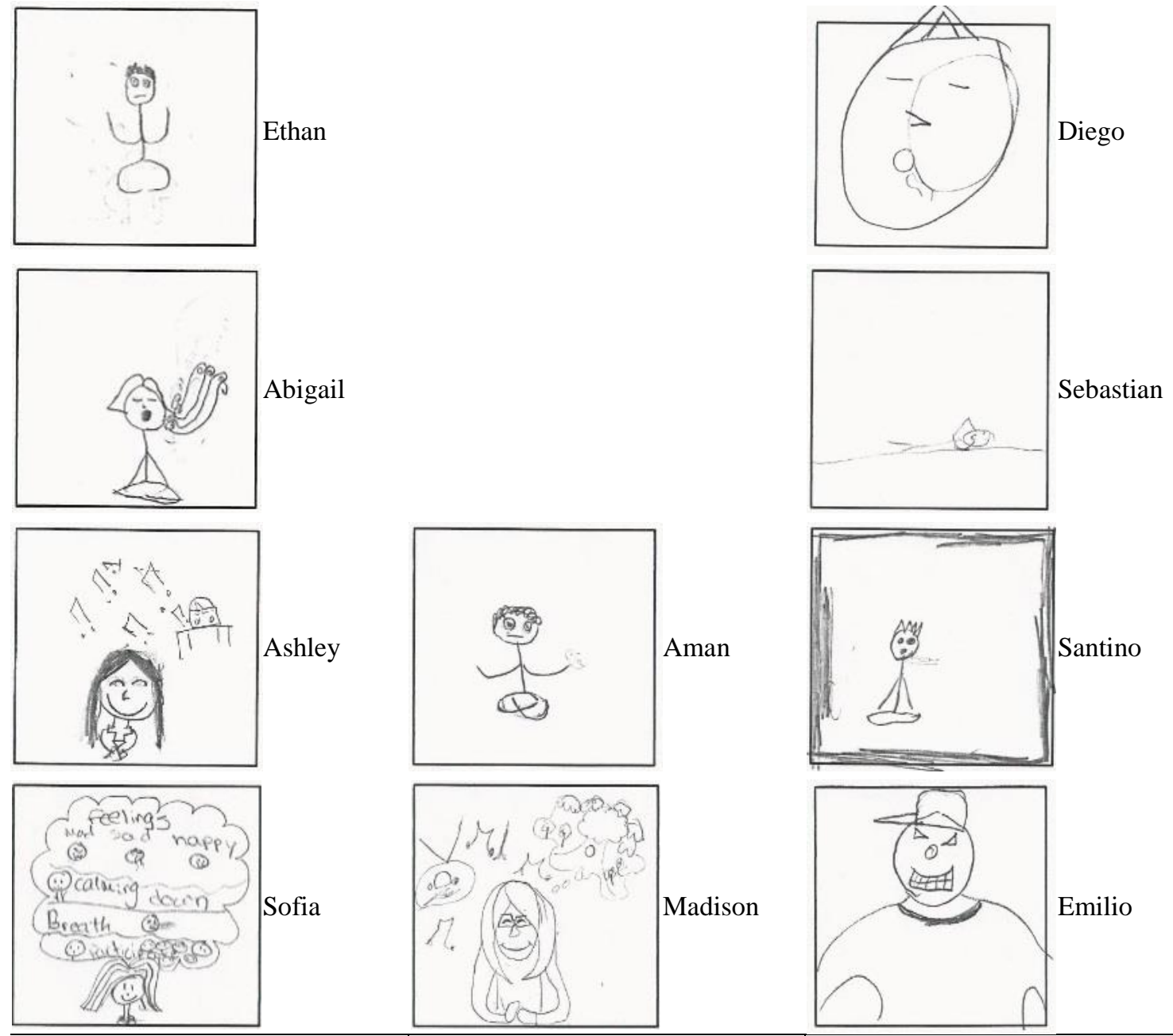

Practicing More
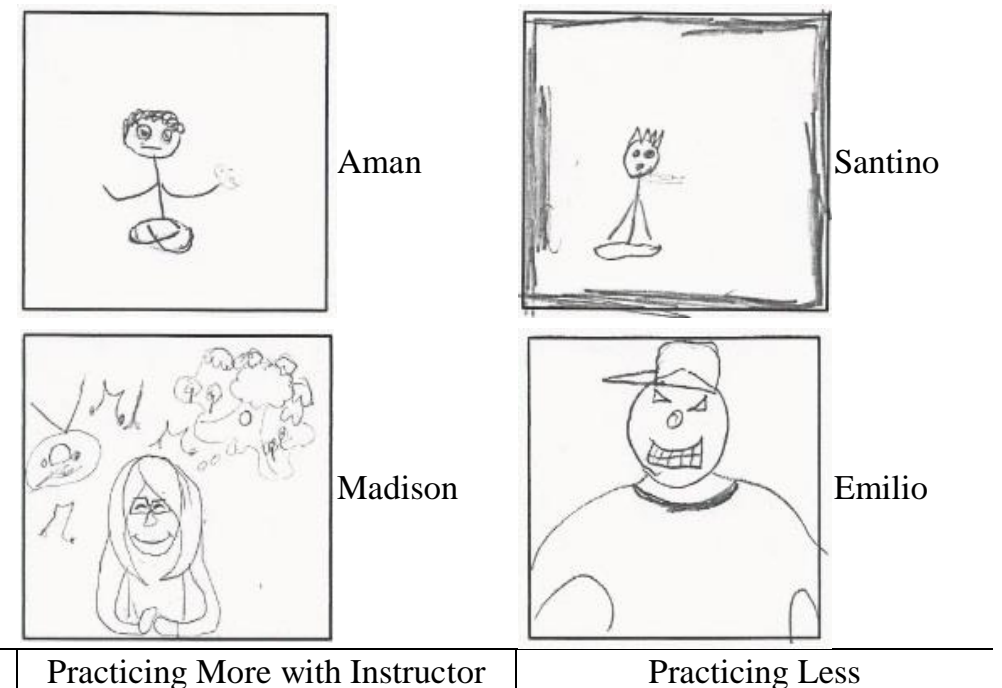

Note: Two of the children (Emma and Jacinta) did not draw a picture. 
Figure 3

Predominant Themes (over 15 excerpts)

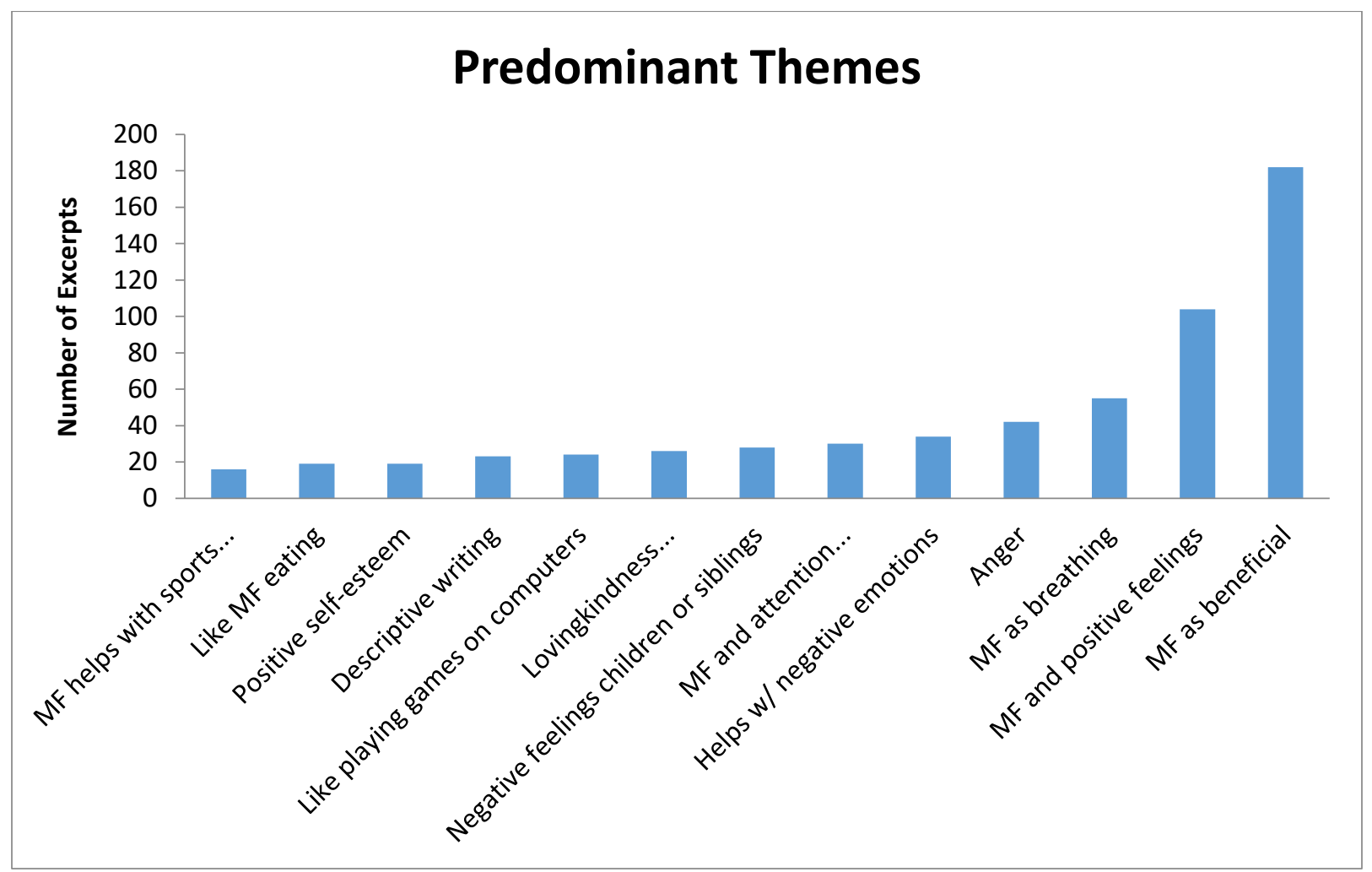


Figure 4

Themes Found in the Journal Excerpts of $\underline{\text { All }}$ of the Students in the Experimental Group

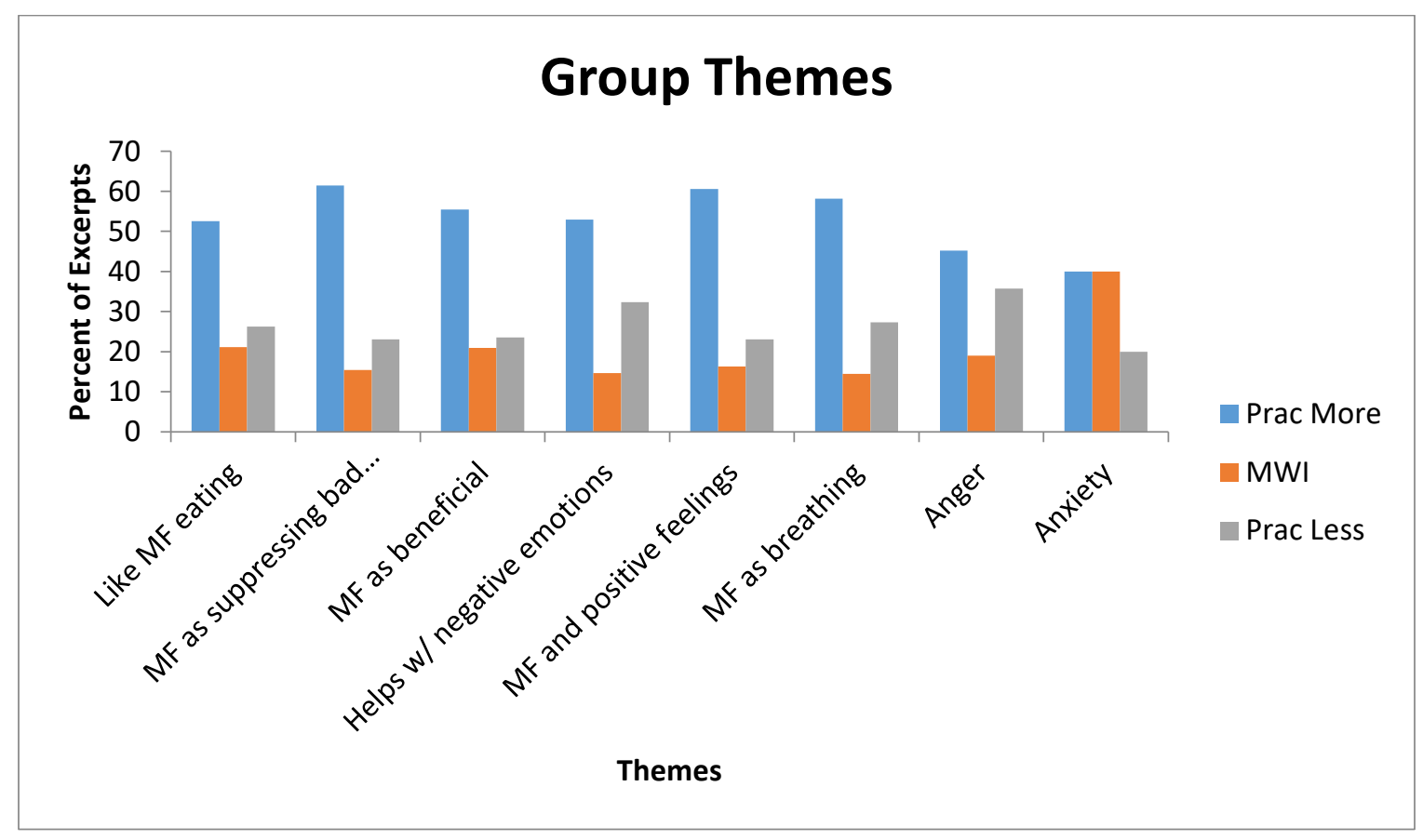


Figure 5

Themes Found in the Journal Excerpts of the Students in the Practicing More Group

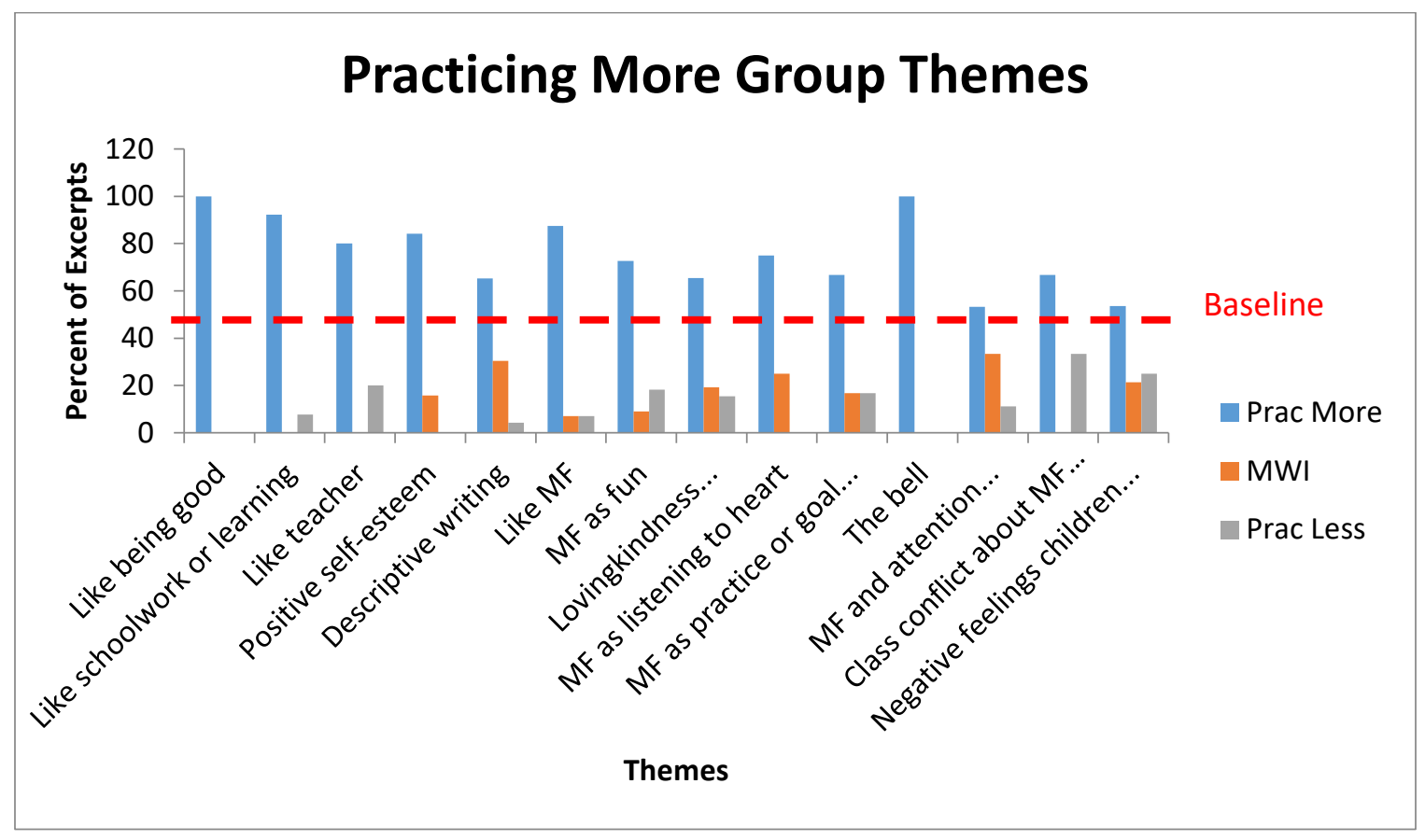

Note: The Practicing More group represented $47 \%$ of the experimental group, so, in this table, any theme where the Practicing More group contributed over $47 \%$ of the excerpts ("Baseline" is at 47\%) indicates the theme's importance to this group. 
Figure 6.

Themes Found in the Journal Excerpts of the Students in the More with Instructor (MWI) Group

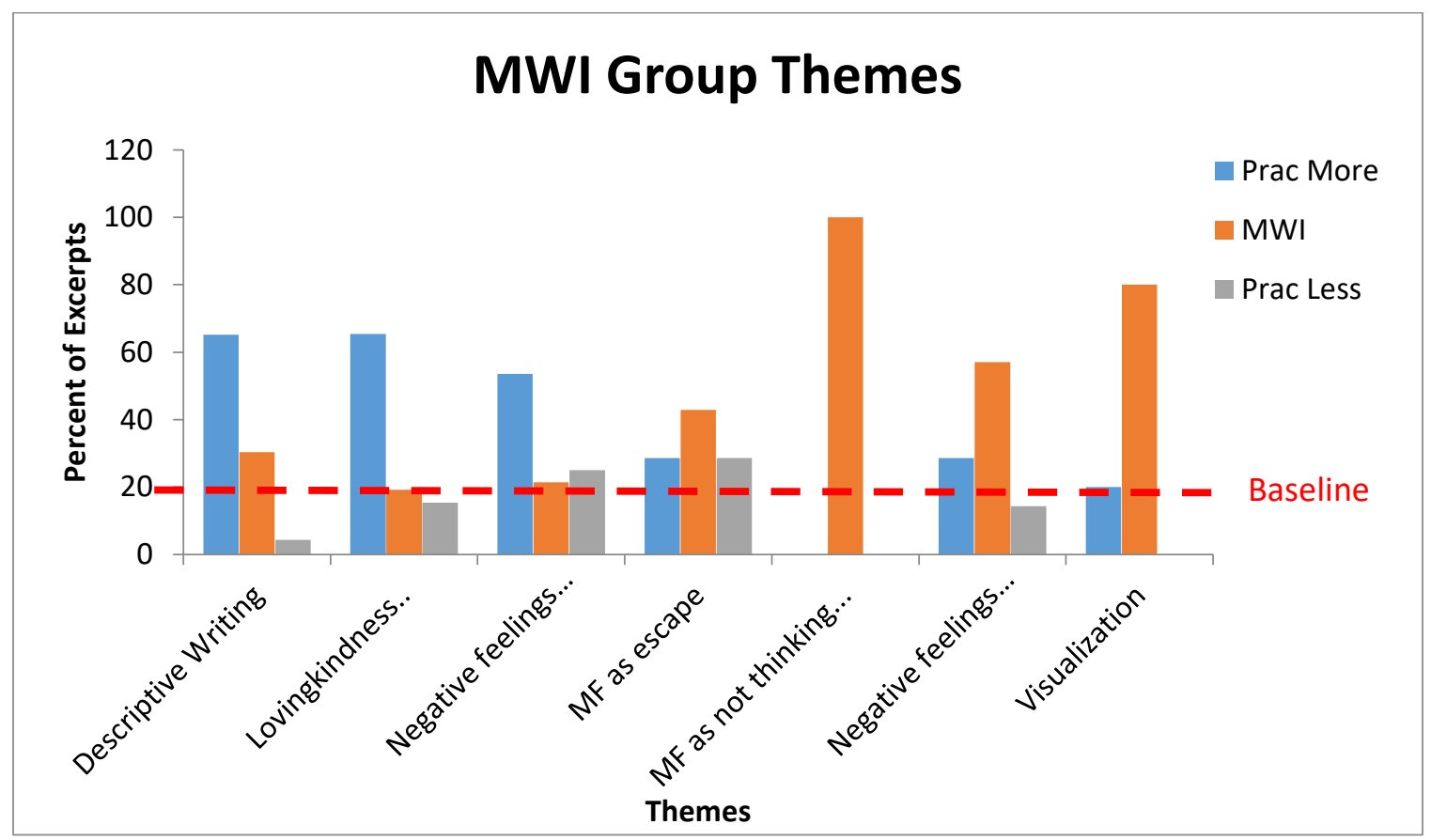

Note: The More with Instructor (MWI) group represented $20 \%$ of the experimental group, so, in this table, any theme where the MWI group contributed over $20 \%$ of the excerpts ("Baseline" is at 20\%) indicates the theme's importance to this group. 
Figure 7.

Themes Found in the Journal Excerpts of the Students in the Practicing Less Group

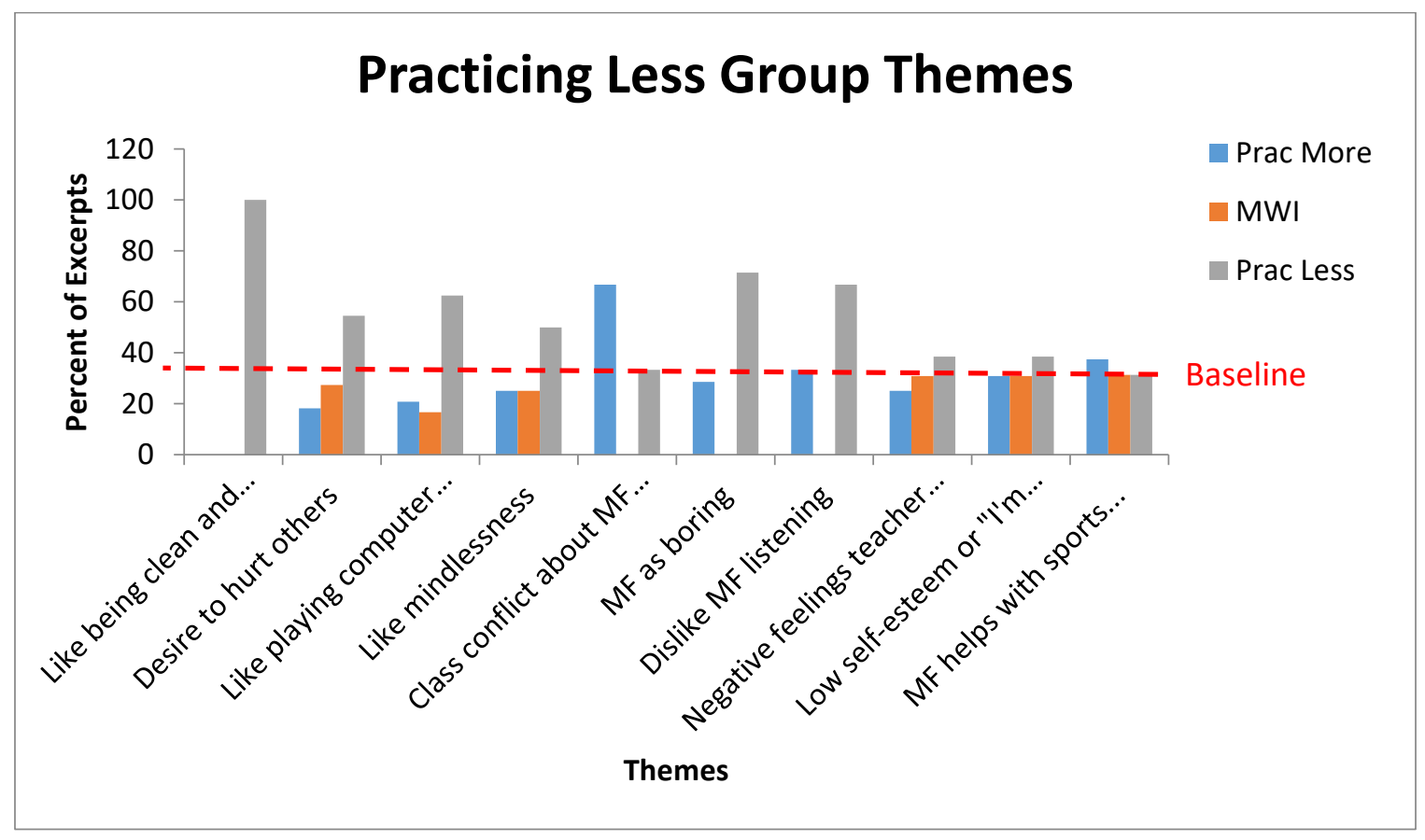

Note: The Practicing Less group represented 33\% of the experimental group, so, in this table, any theme where the Practicing Less group contributed over 33\% of the excerpts ("Baseline" is at 33\%) indicates the theme's importance to this group. 